\title{
New Handbook on Materials Structures, Properties, Processing, and Performance
}

\author{
Ryan M. Deacon ${ }^{1}$
}

Published online: 27 May 2015

(C) Springer Science+Business Media New York and ASM International 2015

I would like to take a moment to acknowledge the accomplishment of one of our editorial advisory board members. Dr. Larry Murr, of the University of Texas El Paso, recently authored a new book entitled Handbook of Materials Structures, Properties, Processing and Performance. This 1152-page handbook covers a wide range of materials science and engineering topics, and will be of interest to scientists, designers, and engineers alike. Published by Springer Reference, this text provides a thorough discussion of several fundamental materials engineering subjects, such as chemical and physical properties, crystal structures, and electromagnetism. These central topics are

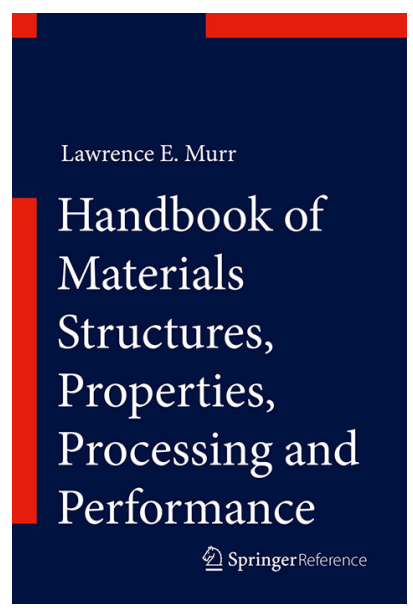

Ryan M. Deacon

ryan.deacon@asminternational.org

1 DuPont Engineering Research and Technology, DuPont Co., Experimental Station, E302/117D,

P.O. Box 80302, Wilmington, DE 19880-0302, USA

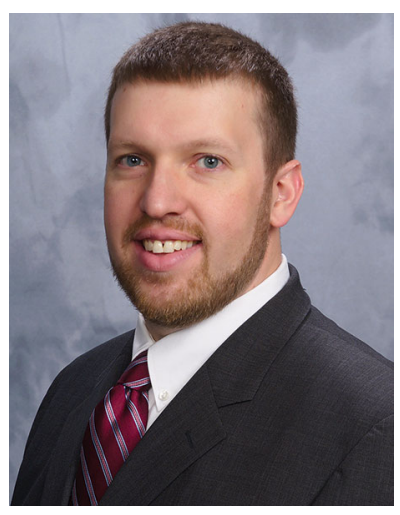

discussed in thorough detail, and both the theoretical and practical aspects are reviewed. The chapter on fracture modes and mechanisms, for example, provides background information on the mechanics of crack nucleation and propagation, while also providing exemplar microstructures and fracture surfaces from failed components.

In addition to these fundamental topics, this book also covers what might be considered the more specialized, and more contemporary materials topics-biomimetics and biomaterials, additive manufacturing, nanomaterials, extreme deformation, and computational modeling. In this manner, the book serves as a review of the essentials, as well as a guide for exploring new frontiers in materials, processing and manufacturing. Magnetic, optoelectronic, and photonic material developments are also covered. While not intended to be the sole source of materials information for any of these particular topics, the book provides a good discussion of the current state and future developments for all of these subjects. Unique perspectives are provided for selected topics that may not otherwise be found in a typical reference book. The chapter on nanotechnology, for example, includes a very interesting discussion on nanotechnology that can be found in historical artifacts, such as pigments and early iron-age weapons. 
Handbook of Materials Structures, Properties, Processing and Performance includes some of Dr. Murr's research results from his nearly 50-year career as a scientist and educator. It is a welcome addition to the current selection of materials engineering reference texts, and will find a home on the bookshelf of many scientists and engineers for years to come. Please join me in congratulating Dr. Murr on this accomplishment. 